Media Industries 8.1 (2021)

\title{
Beyond Streaming Wars: Rethinking Competition in Video Services ${ }^{1}$
}

\author{
Ramon Lobato ${ }^{2}$ \\ RMIT UNIVERSITY \\ Ramon.lobato [AT] rmit.edu.au \\ Amanda D. Lotz $z^{3}$ \\ QUEENSLAND UNIVERSITY OF TECHNOLOGY \\ Amanda.lotz [AT] qut.edu.au
}

\begin{abstract}
Internet-distributed video services have attracted exceptional attention in recent years for their novelty and growth. Business and trade discussions frequently excerpt internet-distributed video services from the broader field of video and narrowly construct their relationship as one of direct competition (e.g., streaming wars). However, there are several distinguishing characteristics of these services that make their relationship more complex. This article explores the multifaceted distinctions and markets within internet-distributed video, including differences in programming, geography, audience, business model, and market position. We also consider what is at stake in different imaginings of video markets for media industry scholarship and policy.
\end{abstract}

Keywords: Streaming Wars, Competition, Subscription Video-on-Demand, Market Boundaries, Netflix, Amazon

Since the early 2000s, the emergence of diverse internet-distributed video services-from global players such as Netflix, Disney, Amazon, and Apple, to an extensive multiplicity of national and regional services including BBC iPlayer (UK), Stan (Australia), Blim (Mexico), and countless others-has transformed the entertainment landscape. In this volatile environment, it is often difficult to sort out who is competing with whom and where the boundaries of different markets lie. Categories such as television, film, home video, and pay TV have become porous as established industrial norms both shift and grow pluriform. Amid this complexity, the dynamics of competition are often misunderstood.

This misunderstanding is evident in recent business and trade press discussion of "streaming wars," a term which entered the lexicon in late 2018 and which has since become a journalistic 
meme widespread in news coverage of video product launches, stock price fluctuations, and subscriber counts, especially in the United States. Indicative headlines such as "The Great Race to Rule Streaming TV" and "Disney, Netflix, Amazon: The Battle for Streaming Survival" give a sense of the winner-takes-all narrative that emerges from such coverage.

This streaming wars discourse has several characteristics. It reduces multidimensional competitive dynamics to a race between a handful of media and technology giants, or presents a battle between new and old media when considerable complementarity exists among the growing array of services. It imagines competition in terms of conflict, victory, and defeat. (Which company will "win" the streaming wars? Will Disney kill Netflix? How many services can survive?) It also divorces internet-distributed services from their wider industrial context. In effect, distribution technology becomes the market boundary, with the consequence that all streaming services are seen to be directly competing with one another. (Curiously, this frame has been pervasive in analysis of video services but is less commonly used in discussing streaming audio services that do compete more directly with nearly identical music libraries and similar functionality.)

Clearly, the streaming wars frame-an artifact of trade commentary and industry hype-does not do justice to the complexity of actually existing video markets. The sudden popularity of this concept does, however, provide a useful opportunity for scholars to critically reexamine the competition dynamics of video services and to ask meaningful questions about the current service ecosystem. In recent work, television industry scholars including Catherine Johnson, Tom Evens, and Karen Donders have begun this important work by reconceptualizing the institutional landscapes of television and video in a manner appropriate to their changing technological contexts. ${ }^{6}$ Working in this tradition, our article asks a further series of questions about competition. To what extent are advertising video-on-demand (AVOD), subscription video-on-demand (SVOD), transactional video-on-demand (TVOD), and legacy payTV services directly competing? What is at stake in claims of a streaming war? And how can we speak about competition among video services in nuanced ways?

To answer these questions, our analysis identifies specific vectors of competition and noncompetition among video services. ${ }^{7}$ We show that rather than creating a zero-sum space of direct competition, internet distribution has in fact introduced further complexity to a video marketplace that was already diverse in distribution technologies, business models, and types of video content-a marketplace also integrated within a larger sphere of leisure industries that seeks consumers' attention, money, data, or all of the above. These points are illustrated through an analysis of current video services in a single territory: Australia. We also consider some policy implications of judging certain services, and their parent companies, as being in the same or in different markets.

\section{Market Boundaries}

A first step in understanding competition in any given media market is to define market boundaries. However, defining a market is no easy matter. Indeed, questions of market definition are among the most complex and materially consequential issues in media law, policy, and regulation. In fields such as antitrust and competition law, setting the boundaries of a 
market to include or exclude certain actors may, as Brett Christophers observes, "generate very different assessments of competition issues, and thus very different forms, vectors and intensities of market intervention and reconfiguration."

It is instructive to consider the language used by major media companies to describe the markets in which their video services compete and how such descriptions are often calibrated to serve the strategic purposes of each company. Media mogul Barry Diller once described video streaming as "a giant arms race" - evoking the familiar streaming wars discourse of direct competition between services. The CEO of NBCUniversal, Steve Burke, has stated that "Everybody is going to compete with everybody."10 BBC Director-General Tony Hall, reflecting on the status of the BBC's on-demand service iPlayer, described the BBC's competitive position as "a medium-sized planet compared to the huge gas giants of the USthe Netflixes, Apples, and Amazons," in a claim that connects companies in multiple industries, with multiple revenue models, and both public-service and commercial measures of success. ${ }^{11}$ In contrast, Netflix CEO Reed Hastings expanded the market boundary further yet in rejecting the idea that Netflix's primary competitors are video services; instead, he identifies the videogame Fortnite, and even sleep, as the company's main competition. ${ }^{12}$ Given this discursive slipperiness, where market boundaries seem to expand or contract depending on who is speaking, the problem of market definition becomes highly significant.

These CEO statements have a performative dimension in that they seek to shape as well as describe a competitive field. Napoli and Caplan refer to this as the "disconnect between how these companies have perceived themselves-and want to be perceived by others-and how they actually function in the contemporary [media] ecosystem."13 In his analysis of Netflix's investor relations, Colin Crawford, building on the work of Timothy Havens, describes the "investor lore"-"narratives and discourses of value which organize, justify and govern [ ...] new industrial practices" - that constructs public understanding of video and entertainment markets. ${ }^{14}$ News, business, and trade press coverage-itself an end-product of the markets it purports to describe-also plays a part in this process, presenting varied and sometimes conflicting visions of markets and their boundaries. ${ }^{15}$

This discursive aspect of competition has been famously analyzed by Michel Callon in The Laws of the Markets. For Callon, any understanding of competition depends on how a market is framed:

Competition, whether perfect or imperfect, is not a starting point but a finishing point. It can exist and really does exist-and that is what makes it so valuable. However, it occurs only when the boundaries, the technical options, have been selected and stabilized, i.e., in a world that is already highly structured and shaped. ${ }^{16}$

As Callon observes, markets have both institutional and discursive dimensions, and a feedback loop exists between the two. For media industry studies-as a field concerned with both institutions and discourse-there are several considerations here. On the one hand, there is the need to understand how specific markets have been institutionally defined and what this means for questions of market power, efficiency, conduct, gatekeeping, and other relevant issues. A second task is to explore how particular market boundaries have come to be made thinkable, common-sensical, legible, and acceptable (their discursive dimension). 
Here, it is helpful to consider the work of Callon, Christophers, and other key thinkers in the critical social science of markets, as well as media scholars such as Patrick Vonderau, whose essays on digital video markets have emphasized the need for "an analysis of the very practices through which markets are constantly made and remade."17

How can these perspectives enrich understanding of video? We suggest that a textured account of audiovisual competition needs to do two things: first, to move beyond monodimensional accounts of competition by paying closer attention to the differences among services, their business models, geographies, catalogs, and operations; and second, to explore how market boundaries are drawn and how such boundaries make markets seem variously larger or smaller, more or less competitive, more or less crowded, depending on who is speaking. Hence, the streaming wars case provides an opportunity to reflect, once more, on the complexity and nuance of video markets and their relation to broader entertainment and leisure markets.

\section{Framing Competition: Video Services in Australia}

For illustrative purposes, let us now consider a specific national market and its mix of video services. Figure 1 presents the twelve most popular internet-distributed video services available in Australia in December 2019. ${ }^{18}$ Australia has been chosen as the site of our analysis for practical reasons, but we expect that some principles of our analysis will be transferrable, and that readers will be able to extend the analysis to include the firms and service categories most relevant to their own national context.

When grouped together as internet-distributed video services, the leading players in the Australian market appear thus.

\section{NETFLIX You Tube

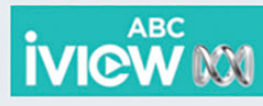 \\ prime video

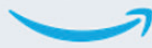

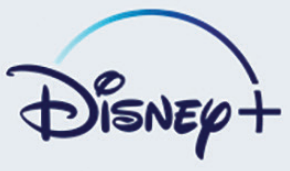
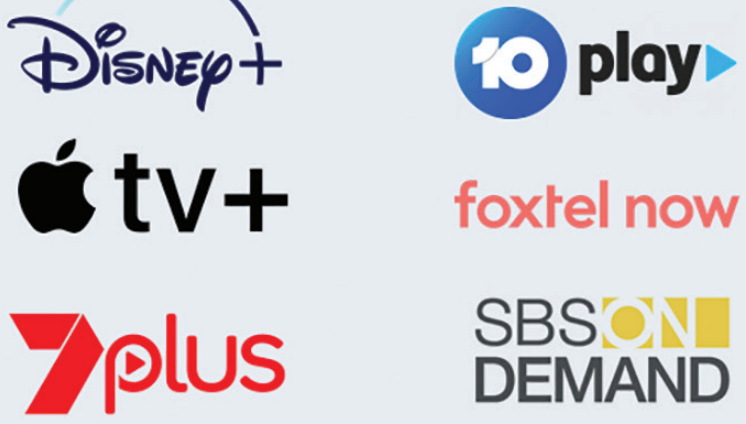

SBS DEMAND
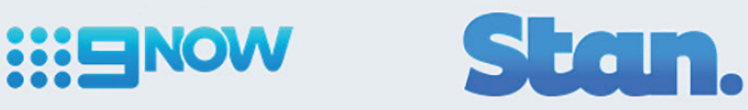

Figure 1. Leading internet-distributed video services in Australia. 
From this perspective (i.e., when the market is defined by distribution technology alone), all the major services for streaming video in Australia appear to be in the same competitive field. Yet a closer look reveals a more complex picture of different service types and categories, including the following:

- Multi-territory, US-based SVODs-Netflix, Apple TV+, Disney+, and Amazon Prime Video.

- YouTube, the world's largest AVOD platform.

- Stan, a national SVOD owned by an Australian media corporation, Nine Entertainment.

- Foxtel Now, the national multichannel operator's over-the-top (OTT) service. ${ }^{19}$

- The advertiser-supported services of three national commercial networks (NineNow, TenPlay, SevenPlus) that mostly allow "catch-up" availability of linear programming and also increasingly feature separately licensed programming.

- The on-demand services of the two public-service broadcasters, ABC iView (government funded) and SBS On Demand (ad-supported). ${ }^{20}$

As this breakdown suggests, the category of streaming video is in fact a place-holder for a multiplicity of different services with distinct histories, libraries, and content strategies. How can we understand the interactions between these services? Are they all in direct competition? Research from other national contexts suggests a need for caution here, as services are often competing for quite different things, and many are complementary rather than directly competitive. Ampere Analysis observes that "the interaction between SVoD and pay TV service uptake is complex and varies significantly by market," with territories including the United Kingdom exhibiting a high degree of complementarity among services, while other territories (notably the United States) exhibit some evidence of substitution (cablecutting). ${ }^{21}$ This makes sense given the varied range of services in the market before SVOD in different countries and their creation of different value propositions and satisfaction levels. In the United States, the substitution occurs between cable/satellite and virtual multichannel video programming distributors (vMVPDs), which offer fundamentally the same product distributed using a different technology. The answer to the question "who is competing with whom?" also depends on what specific metric is under consideration (viewing time, subscriber numbers, revenues, and so on) and whether services are also competing for inputs such as production resources, talent, and scripts. ${ }^{22}$

Let us now consider in more detail some vectors of differentiation that organize the field. Here, three considerations are especially important: (1) content characteristics; (2) revenue source, business model, and value to the firm; and (3) geographic scale. ${ }^{23}$

\section{Content Characteristics}

The first key distinction among these video services is the variation in content they offer, including their specialty genres, original productions, and the depth and breadth of their catalogs. The extent of variation is such that most of the above services are not readily substitutable: each offers exclusive content and a particular mix of genres and program types.

At a general level, clear content differences can be identified in the size and variety of the libraries of content these services offer, as Figure 2 shows. 


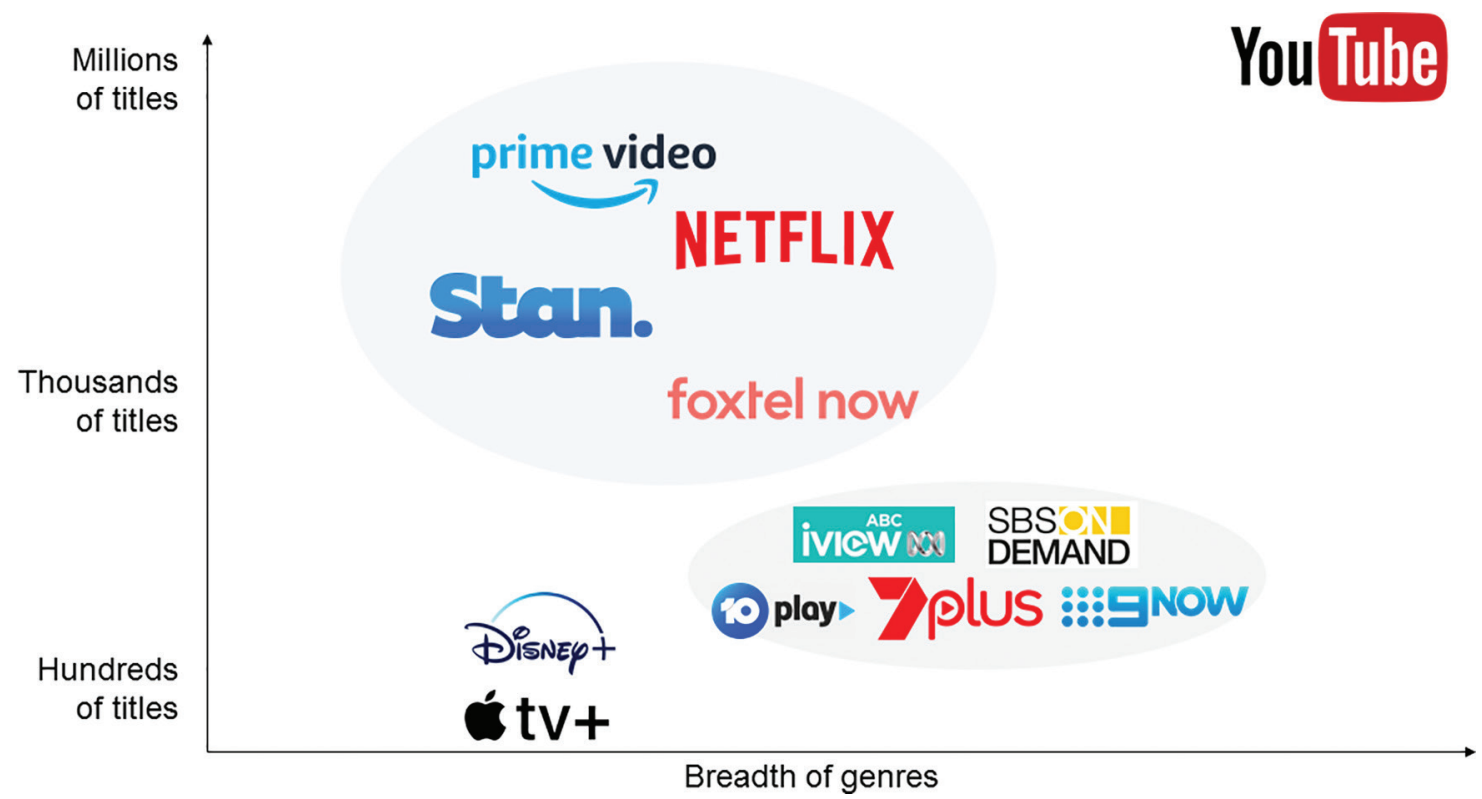

Figure 2. Internet-distributed video services in Australia organized by content characteristics: genre breadth and catalog depth.

Figure 2 charts the differences among the libraries. The SVODs (Prime Video, Netflix, Stan, Foxtel Now) typically have catalogs in the low thousands of titles: Stan offers half of the roughly five thousand titles offered by Netflix Australia, which is about a third of what Prime Video offers. ${ }^{24}$ The services maintain these titles for a duration measured in years. The broadcasters' services, in contrast, typically have a smaller catalog (typically in hundreds of titles) consisting of original network productions that are available for weeks or months rather than years and a smattering of back-catalog titles (mostly from the United States). These services rarely have full series available. The broadcaster services remain primarily "catch-up" services that maintain residual norms of the ephemerality of "television" scheduling, while SVOD services are more characteristic of a precursor such as video rental. Apple here assumes an outlier position: the Apple TV+ library consists of a small number of premium exclusive shows initially released on a weekly basis. The library differences indicated by the cluster evident in Figure 2 suggest subsets of services that may "compete"-at least on the basis of offering similar content scale and viewing experience-while the relationship between the subsets is more complementary.

The services are also distinguished in terms of the variety of content offered in their libraries. A distinction in strategy occurs between those that offer several types of programming but less depth in any one (generalist) and those that offer lesser range in types of programming but more depth (specialist). The SVODs tend to offer a deep but restricted mix of genres, compared to the much broader but shallower offering of the broadcasters' services (which cover the full spectrum of news, sports, light entertainment, and local content provided by broadcasters). Consequently, viewers seeking local news cannot easily switch from a broadcast 
service to an SVOD in a manner that makes them interchangeable. As an analogy, like internetdistributed video, "store" is a general category of a place that consumers buy goods; however, all stores do not directly compete. An office goods store competes as meaningfully with a teen fashion store as a film service competes with the one offering sports. Just as broadcast and multichannel television has simultaneously offered news, sport, fiction, game shows, and films in different dayparts or channels, internet-distributed video content likewise reproduces this range of desired content across the diverse marketplace of services.

Our point here is a basic but important one: all video is not interchangeable, and consequently, these various services do not compete directly in the manner suggested by the blunt criterion of distribution technology (i.e., they all offer internet-distributed video). ${ }^{25}$ As Kevin Sanson and Gregory Steirer have argued, the industrial logics of streaming video are not uniform. ${ }^{26}$ Furthermore, viewers' regard of these different services derives from more than content characteristics. That content is part of an overall value proposition that includes type of content, depth of content, user experience (ability to find desired content, ease of use, interface), and whether viewers pay through a fee or the tedium of commercials. Internet-distributed video services are highly differentiated by these measures.

\section{Revenue Source, Business Model, and Value to the Firm}

A second distinguishing characteristic of video services includes the intertwined considerations of revenue source, business model, and value to the firm. Revenue source is often glossed over, or erroneously conflated, in industry commentary about video services. Despite their considerable differences in content and geographic scale, multi-territory SVODs (Netflix), national SVODs (Stan), and internet-distributed services from pay-TV providers (Foxtel Now) are all funded directly by subscriber payment. YouTube, in contrast, is funded through advertising and cross-subsidized by its corporate parent, Google, although it also offers an ad-free subscription product in YouTube Premium. Public-service media streaming services (ABC iView and SBS) receive public funding, although the latter also relies on advertiser funding.

Such differences in what is traded-subscriber fees, attention, and public funds-lead the broad field of internet-distributed video to fail what Aspers has described as a fundamental definition of a market-that it is about trade of a common thing. ${ }^{27}$ Following Aspers, separate markets exist among those services that compete for subscriber fees and those that compete for advertiser dollars. By shifting the lens in this way, we see how SVODs compete with other leisure services such as gaming and how AVODs compete with ad-funded linear services, other ad-supported media, and growing forms of ad-spending such as search and social media-in an effort to convince advertisers that they offer optimal audiences and tools for addressing them.

What are the competitive relations between and within each of these revenue categories? Advertiser-funded services do not compete with subscription services for revenues because the former are free to the viewer and the latter require payment. In other words, their business models can be understood as complementary in the same way that broadcast television and video-store rentals in a bygone era were complementary from the point of view of revenue source. Viewers, at least those with an internet connection and sufficient awareness of 
the various services on offer, consequently all have access to a wide variety of monetarily free, advertiser-funded services, but will likely limit their purchase of subscription services based on their disposable income, the content differentiation noted above, and the value proposition offered. There is a monetary budget constraint among the subscription services, but a "time/attention constraint" in advertiser-funded services. These differences are crucial to distinguishing content strategy and how services seek to attract viewers.

As a result of these varying revenue sources, different internet-distributed video services have different criteria for success. While all compete for viewer attention, the metrics that really matter, and how and why they matter, are distinct to each revenue source. For advertiser-funded services, the most important metric is the revenue generated from advertisements-which is closely linked to overall viewing hours. The broadcasters, the broadcasters' AVOD services sell attention in a manner similar to their linear broadcasts.

In contrast to the case of ad-funded services, the baseline metric for success of SVODs including Stan, Netflix, and Disney+ is their number of subscribers. Netflix is unusual among these services in being the only pure SVOD service that is overwhelmingly reliant on subscriber payments and unable to cross-subsidize and integrate its video service with other lines of business. For Netflix, metrics such as time spent on the service are likely useful as predictors of satisfaction with the service necessary for continued subscription (heavy usage might generally predict less likelihood of a user canceling their subscription). However, increasing viewing hours is not Netflix's primary aim. Viewing hours and behavior (e.g., binge-like viewing) are proxies to Netflix for the metric that really matters to the company and its shareholders-subscriber numbers. Purely publicly funded internet-distributed video services (ABC iView) and hybrid public-funded/ad-funded services (SBS On Demand) have yet other criteria for success. While these services are keenly aware of their digital viewing/ engagement metrics, their public-service mission means that they see these metrics through the prism of considerations such as public impact, public value, and Charter fulfillment. ${ }^{28}$

Overlooking the differences among what these video services trade video for leads to misunderstanding competitive dynamics. One common misunderstanding focuses on the belief that there is a common market for attention. This idea holds that attention to SVODs is "lost" by linear services in a manner that diminishes advertising revenue. The actual impact likely appears paradoxical though completely in line with classic economic theory. Although linear viewing of broadcasters declined markedly in the United States with mainstreaming of cable service, such that their share of viewers declined from 90 to 64 percent during the 1980s, and then to 46 percent by 2005, advertisers' spending on them did not decline. ${ }^{29}$ The gross rating points (number of ad exposures to viewers) available declined, but that decreased supply, matched with constant demand, led the price of reaching those viewers to increase so that television ad spending, on the whole, has remained remarkably constant despite diminishing audience size (advertisers pay the same amount to channels, but pay more per exposure). In the last decade, advertisers have moved some spending from television (decreasing demand), but that results from the existence of other advertising tools such as search and social media that offer advertisers a better-or different-value proposition, rather than a function of attention gathered by SVODs.

Business model ties revenue source and content strategy. Because these services trade video for different things-payment, attention-they build business models and content strategies 
that vary accordingly. An AVOD service derives value from mass viewing, either from having mass popularity or a mass of videos all gathering attention (YouTube), or from attracting the kinds of viewers that attract premium advertising rates. In contrast, SVODs must offer content viewers are willing to pay for. As we explore next, many services are not focused centrally on that payment (Apple, Amazon) or might be using the SVOD as a way to more directly monetize libraries of intellectual property created for other licensors (Disney+), while others yet are built around providing a video service distinctive and valuable enough to warrant payment (Stan, Netflix).

As these examples suggest, there is great variation among the revenue sources and thus primary metrics of success among internet-distributed video services. This variation complicates any attempt to place these services into a singular competitive field. Public service, ad-supported, and subscriber-supported services trade video content for different things, and they judge their success accordingly. Caricatures of competition-for example, narratives of Netflix "displacing" the BBC, or a battle royale between American tech giants such as Amazon, Netflix and Apple-are misleading. While services ultimately vie for the time attention, and sometimes payment of viewers in their target markets, the metrics that really count to each category of funding are distinct, and not a zero-sum dynamic.

A further defining characteristic is the relative importance of video services to the overall strategy and revenue of the owning firm. For the leading US technology firms offering internet-distributed video services-Amazon, Google, Apple-these video services provide benefits for other business objectives, such as collecting data or expanding e-commerce or hardware sales. We can therefore draw a further distinction between at least three categories of video service: those where video is the primary or only activity (Netflix), those where video forms part of a wider set of media activities (including Disney+, Stan, and the commercial TV and public-service operators offering online catch-up services), and those where video activities are secondary to the larger business objectives of the parent company (Apple, Amazon, and Google/Alphabet). ${ }^{30}$

Value to the firm provides the final component of this cluster of distinguishing characteristics. The revenue derived from video service is the whole of some businesses and quite marginal to others, leading it to have different importance within different firms. This also has implications for how we understand dynamics between firms. Seeing Australian video services from this perspective allows us to draw finer distinctions between what could otherwise be glossed as "Big Tech" companies, which have been conflated in acronyms such as FAANG (Facebook, Amazon, Apple, Netflix, Google), GAFA (the same minus Netflix), and poorly differentiated anxiety about "tech" and "platform" companies. The value of Apple TV+ and Prime Video to their parent companies (Apple and Amazon) is largely indirect and of lesser overall significance to the revenue base than for "pure" video services like Netflix or those integrated in media conglomerates. For example, Netflix's revenues in 2019 were approximately US\$20 billion, the vast majority of which derived from user subscriptions. In contrast, Amazon Inc.'s overall revenues for the same period were US\$280 billion, with Prime Video essentially adding value to Amazon Prime memberships and thus enticing consumers to increase their retail spend with Amazon. ${ }^{31}$ Netflix is fundamentally different from these other companies because of its exclusive reliance on video. Unlike Amazon, Google, and 
Apple, Netflix does not have the luxury of cross-subsidizing its video operation with other sectors. Its continued commercial viability relies on its ability to attract subscribers.

Another structuring difference among the corporations offering internet-distributed video services is the ownership of large libraries of intellectual property, production facilities, and established content brands that enable vertical integration of video production and circulation. The historical dominance of the United States in creating this intellectual property has advantaged US media conglomerates that are building internet-distributed services to leverage their libraries of content. Services such as Hulu, CBS All Access, and, to some degree, HBO have offered internet-distributed video built on this logic for some time, and these services provide the basis for more recent launches of Disney+, Paramount+, and HBO Max that are larger and more strategic efforts to collapse layers of circulation and more directly connect companies that produce video with consumers' dollars. Importantly, these services based on deep catalogs of preexisting intellectual property should be conceptually distinguished from the services offered by Amazon, Apple, and Netflix, not because they are not "tech" companies, but because of the underlying economics of their businesses that derive from owning libraries of video offerings.

Firms that primarily derive revenue from distribution infrastructure and internet service providers (ISPs) can also use free or discounted access to proprietary internet-distributed video services as a tool to drive take-up of internet plans (HBO Max, Peacock in the United States). Such cases can be identified around the globe. The advantage of this vertical integration could be particularly acute in the United States, where the elimination of net neutrality provisions enables conglomerates that provide internet service to throttle or seek rents from services competing with those they own.

A further consideration is how ISPs might use video services as loss leaders-in a way comparable to, but still distinct from, companies such as Apple, Amazon, and Google-to offer video services that seem to compete, but have quite different strategic purposes for their companies. These companies offer video for varied reasons, and those reasons lead to different priorities in spending and willingness-and ability-to accept financial losses. Seeing internet-distributed video as a single competitive field therefore fails to account for the significantly different measures of success that govern the operation of different services.

\section{Geographic Scale}

Geographic scale is an important consideration for any analysis of media competition because a common feature of media industries-especially internet-distributed video-is very low marginal costs, which incentivizes firms to seek economies of scale. In other words, most costs are bound up in the making of the good-a television show or film-while sharing the show with additional viewers attracts little or no further cost. Thus, the industry is incentivized to distribute a title across the widest possible audience most efficiently to recoup the content investment-whether paid in attention or time. The distribution architecture of the internet has allowed companies seeking to provide multi-territory distribution with more direct ways of reaching multi-territory audiences than the norms afforded by broadcast and 
multichannel distribution-although it is important to acknowledge that moving-image distribution has been multi-territory for most of its history. ${ }^{32}$ Commercial success for internetdistributed video services does not require global or multi-territory scale; however, available scale does significantly affect the content and strategy of the service.

Rearranging our video services according to geography produces yet another organization of the competitive field. A key distinction emerges between multi-territory services (YouTube, Prime Video, Netflix, Disney+) that operate across a large number of countries and national services that do not benefit from global economies of scale and are available only in one country (Stan, ABC iView, SevenPlus, TenPlay, NineNow, and SBS On Demand).

There is a profound difference between the cost structures of multi-territory and national SVOD services. The scale of Netflix's original production budget-US\$15 billion in 2019-is often cited as an indication of its outsized power, ${ }^{33}$ but Netflix is servicing 148.8 million subscriber accounts with that budget. Per subscriber account, that spend is US\$100.80. ${ }^{34}$ To draw valid comparisons, we must consider budgets in relation to subscriber levels, although there are competitive advantages in scale. Available scale also enables different content strategies. A multi-territory service with an extensive subscriber base such as Netflix can target program tastes and sensibilities that might not be significant at a national level but become significant with multi-territory aggregation. ${ }^{35}$

Netflix is able to spend far more on programming overall, but that programming is also designed to service viewers in various languages and a wide array of taste cultures. Netflix cannot offer the depth of local content associated with national services-certainly not in each of the markets it serves-which again points to a degree of complementarity between Netflix and national services. ${ }^{36}$ Indeed, national video services are likely to offer very different content than those with multi-territory aims and are also likely to have far fewer dollars to spend. Recent analysis by Variety and Ampere Analysis note the high amount of local content that many dominant national services carry. For example, Germany's Joyn offered 66 percent German titles (Netflix 4 percent), United Kingdom's ITV Plus 65 percent (Netflix 7 percent), and India's ALTBalaji 76 percent (Netflix 8 percent). ${ }^{37}$ In the European context, research by the European Audiovisual Observatory has also established that domestic video services are more likely to feature higher levels of local content. ${ }^{38}$ Different viewers prioritize domestic and US content differently; hence, services that seek to offer domestic versus foreign content are somewhat more complementary than competitive with those offering mostly US titles. In the global market, US services compete more directly with each other because all rely heavily on US-produced content.

Another point of differentiation within the major multi-territory SVOD services (Disney+, Amazon Prime Video, Netflix, Apple TV+) is the extent to which they engage multi-territory production-a distinction that blends content and geography. Netflix has progressively expanded its original production worldwide, shooting original series and movies in more than thirty countries. Although the "streaming wars" narrative has most frequently given top billing to the battle between Netflix and Disney+, to date, Disney's investment in original international production remains minimal compared to Netflix. In other words, there is a notable difference in operational dynamics between national services and multi-territory services and, furthermore, between the multi-territory services committed to significant international 
production investment (especially Netflix) and those using a "US export" model (Apple and Disney, at this stage). Although Netflix also started as a US-only service, proper conceptualization of the relationship among these services requires addressing these distinctions.

Suggesting a slightly different dynamic, Amazon has commissioned content outside the United States, but far fewer titles, and mostly only in countries that are retail priorities such as India, Germany, and the United Kingdom. Amazon's video strategy is intricately connected to the geography of its retail business. It uses the video service to drive Prime memberships that encourage more retail shopping in countries where it has an expansive retail offering. Its original video production strategy likewise preferences those countries that Amazon has targeted for retail development, as evidenced by expensive Amazon originals such as Inside Edge (an Indian cricket drama) and Beat (a German thriller). In other countries, the video service may simply be a strategy of preparing the market for eventual retail service.

As this section illustrates, multiple attributes transect the internet-distributed video services in meaningful yet inconsistent ways. The competitive field looks very different depending on whether services are sorted by their content and value proposition, their revenue source and business model, or geographic reach. This analysis has only considered these characteristics among internet-distributed video services, but expanding that field to include video distributed using other technologies such as DVDs, cable and satellite TV, and linear broadcast television adds yet further complexity. Viewers choose among video distributed by many services, including broadcast and multichannel (cable and satellite) services, that coexist with internetdistributed video. Defining a market according to distribution technology alone may be the least helpful distinction in developing sophisticated analyses of the extent of the competition, complementarity, and substitutability in domestic video markets.

\section{Competition, Market Power and Policy}

In this article, we have argued for a nuanced view of competition in internet-distributed video as a means to move beyond the reductive frame of streaming wars. We have shown that there are multiple vectors that structure and define markets discrepantly. Content characteristics, business model/revenue source, and geography, among other factors, subdivide these services to create more complementarity than commonly recognized.

Why does this matter? Beyond the obvious need for analytical precision, there are several reasons why a multifaceted conceptualization of competition among video services is important. Competition matters to the extent that it shapes people's access to content, the price they pay, the diversity of content available, and the ability to switch between providers. There is a clear public interest in clarifying understanding of who is competing with whom in video services and on what basis: this is essential for the purposes of effective media regulation as well as for meaningful analysis, critique, and scholarly investigation. Defining markets by distribution technology alone is insufficient for conceptualizing the multiple competitive relations among streaming video services, and-just as importantly-between those services and legacy linear services. However, other implications need to be considered as well. 
For example, changing understandings of competition require that we also reconsider our assumptions of market power-including the market power of key players like Netflix, Google, Apple, and Amazon-precisely because the market shares of relevant firms expand or contract when we move the market boundary. In its investor-targeted long-term view, Netflix strategically identifies its competitors as including "linear networks, pay-per-view content, DVD watching, other Internet networks, video gaming, web browsing, magazine reading, video piracy, and much more." ${ }^{39}$ Hence, Netflix argues for the largest market possible and makes its own position in that market appear modest. Apple and Amazon have similarly sought to present themselves as competing within very large and multidimensional markets, such as entertainment and retail, rather than achieving positions of dominance in smaller markets, such as online grocery goods or smartphone hardware. The argument that adsupported YouTube meaningfully keeps subscriber-funded Netflix "in check" through idealized competitive forces within a single market is therefore questionable. Rather, these two internet-distributed video services have outsized influence within distinct markets, and competition policy needs to be alert to the implications of that scale.

As we have shown, changing our view of a video market can dramatically shrink or expand the boundaries of competition, and thus alter a company's perceived position of market dominance or vulnerability. Is Netflix competing with every leisure activity, including sleep, or is it dominating a small market of multinational SVOD services? Does its giant status prevent others from entering the market, or does it offer a particular value proposition of ondemand US content that leaves ample room for other services with a more local focus? The answers depend very much on looking past the common feature of using the internet to distribute video, to factors such as what content do services offer, what revenue model and business strategy do they use, in support of what corporate aim, and how do factors of multi-territory or single territory scale circumscribe the competitive field.

As policy-makers grapple with the challenge of addressing regulatory imbalances between different forms of video-and as some countries consider a shift toward a "harmonized" regulatory environment where media services would have the same obligations regardless of their mode of distribution ${ }^{40}$-the stakes of these questions increase, along with the risks of unintended consequences. For example, should domestically owned services face different policy than those based outside the country? Should annual revenues govern policy application? Should services with different value propositions be regulated the same way?

Without doubt, the advent of internet-distributed video services has complicated regulatory regimes that were already overburdened by the need to sort policy for discrepant distribution technology with discrepant funding structures that increasingly made once-national television ecosystems increasingly multi-territorial in terms of the ownership of services, channels, and producers. There is no single policy approach revealed by the analysis here; rather, the complexity of the ecosystem points to the need to go back to first principles and the aims behind policy.

In many countries, the ecosystem of video services is profoundly and irreversibly changed. Policies made in eras of scarcity rarely remain fit for purpose, and supports introduced to ensure domestic content within markets constrained to domestic 
services grow ineffective as viewers respond to expanded choice among video services and among forms of leisure more broadly, some of which offer superior tools to advertisers. Decades of unrestrained commercial television growth has halted as viewers take their attention away from services with unfavorable programming or a suboptimal experience. As a result, the video marketplace grows more bifurcated between live programming attractive to mass audiences (and thus valuable to ad-supported services) and scripted content targeted to increasingly specific tastes and sensibilities (well suited to viewer payment). The business, technology, and content are disaggregating from old norms and reconfiguring with regard to new capabilities. The optimal policy response builds from these new dynamics and reassesses previous goals of what is possible and necessary in accordance with this reality.

Alongside concerns about competitive markets and their microeconomic dynamics, we note that policy debates about video regulation-especially in smaller nations-are often less concerned with the nuances of a multidimensional competitive space than with more immediate questions of national competitiveness. Imperatives such as supporting national champions (domestic media and technology firms), extracting tax revenue from multinational companies, and sustaining an appropriate mix of local and imported content have already surfaced as major concerns for national regulators charged with navigating the rapidly changing video landscape. Hence, the geopolitical question of competition between nations-as well as within national markets-also comes to the fore.

As this discussion suggests, there is much at stake in how the competitive field is defined. Each of the frames through which audiovisual competition can be imagined-whether between specific services, service types, firms, sectors, or even nations-tells a different story about who has power and influence in a given market. Advocating for a particular frame is not the purpose of this article, but we would suggest in closing that both academic scholarship and the public interest are best served by analyses that are transparent and reflexive about their market definition process-and these decisions should not be on the basis of distribution technology, nor the function of distributing video, alone.

${ }^{1}$ The authors acknowledge the support of the Australian Research Council Discovery scheme (project DP190100978) and the expert research assistance of Alexa Scarlata.

${ }^{2}$ Ramon Lobato is Associate Professor (Australian Research Council Future Fellow) in the School of Media and Communication at RMIT University, Melbourne.

${ }^{3}$ Amanda D. Lotz is Professor and leader of the Transforming Media Industries research program in the Digital Media Research Centre at Queensland University of Technology.

${ }^{4}$ Jonah Weiner, "The Great Race to Rule Streaming TV," New York Times, July 10, 2019, https://www.nytimes.com/2019/07/10/magazine/streaming-race-netflixhbo-hulu-amazon.html (accessed September 23, 2019).

${ }^{5}$ Christian Hewgill, "Disney, Netflix, Amazon: The Battle for Streaming Survival," BBC News, April 12, 2019, https://www.bbc.com/news/newsbeat-47692925 (accessed September 23, 2019). 
${ }^{6}$ Catherine Johnson, Online TV (London: Routledge, 2019); Tom Evens and Karen Donders, Platform Power and Policy in Transforming Television Markets(Basingstoke: Palgrave Macmillan, 2018).

${ }^{7}$ This aspect of the argument has been briefly explored in an earlier article-see Amanda Lotz, Ramon Lobato, and Julian Thomas, "Internet-Distributed Television Research: A Provocation," Media Industries 5 (2, 2018): 35-47.

${ }^{8}$ Brett Christophers, "The Law's Markets," Journal of Cultural Economy 8 (2, 2015): 125-43.

${ }^{9}$ Alex Sherman and Dain Evans, "How Streaming Wars between Disney, Netflix and Others Will Change TV," CNBC, August 10, 2019, https://www.cnbc. com/2019/08/10/how-streaming-wars-between-disney-netflix-others-willchange-tv.html (accessed September 23, 2019).

${ }^{10}$ Natalie Jarvey, "NBCUniversal CEO Steve Burke Explains How New Streaming Service Will Take Shape," The Hollywood Reporter, January 14, 2019, https://www. hollywoodreporter.com/news /nbcu-ceo-steve-burke-talks-forthcoming-stream ing-service-future-hulu-impact-nbc-news-1176015 (accessed October 17, 2019).

11 Tony Hall, "Roscoe Lecture," Liverpool John Moores University, November 2, 2017, https://www.bbc.co.uk/mediacentre/speeches/2017/tony-hall-roscoe (accessed September 17, 2019).

12 Rina Raphael, "Netflix CEO Reed Hastings: Sleep Is Our Competition," Fast Company, November 6, 2017, https://www.fastcompany.com/40491939/netflix-ceo-reedhastings-sleep-is-our-competition (accessed October 17, 2019).

${ }^{13}$ Philip M. Napoli and Robyn Caplan, "Why Media Companies Insist They're Not Media Companies, Why They're Wrong, and Why It Matters," First Monday 22 (5, 2017), http://dx.doi.org/10.5210/fm.v22i15.7051.

${ }^{14}$ Colin Crawford, "Fictitious Capital: Netflix and the New Narratives of Media Value in Platform Capitalism," proceedings of Intersections, Cross-Sections conference (Toronto: Ryerson University and York University, 2019), 18; and Colin Crawford, Netflix's Speculative Fictions: Financializing Platform Television (Lanham, MD: Rowman and Littlefield, 2020).

15 The analyst Matthew Ball-a former Amazon Prime Video executive-has repeatedly questioned the dominant narrative of streaming wars, offering instead a nuanced account of the political economy of streaming services and their parent companies. Ball's various essays are available at https://www.matthewball.vc/all.

${ }^{16}$ Michel Callon, The Laws of the Markets (Malden, MA: Blackwell, 1998), 44-45.

${ }^{17}$ Patrick Vonderau, "Beyond Piracy: Understanding Digital Markets," in Connected Viewing: Selling, Streaming and Sharing Media in the Digital Age (London: Routledge, 2013), 99-123; see also Patrick Vonderau, "The Video Bubble: Multichannel Networks and the Transformation of YouTube," Convergence 22 $(4,2016): 361-75$.

18 To determine this initial sample, we consulted two resources: the Nielsen Streaming Report Australia (https://digitallandscape.nielsendashboards.com.au/streamingreport) and the Australian Communications and Media Authority Communications report 2018-2019 (https://www.acma.gov.au/publications/2020-02/report/com munications-report-2018-19), which uses data from the Roy Morgan market research 
agency. We then identified the top services in each report to establish a sample of the major streaming services in Australia (i.e., those listed in both indexes). To this list of services, we have added Apple TV+ and Disney+, which were not available in the Australian market at the time of these studies. We acknowledge the partial nature of these underlying metrics and the difficulties inherent in measuring streaming audiences. The purpose of our analysis is not measurement but rather to explore the consequences of classifying and comparing video services into different competitive fields.

19 The Australian pay-TV provider Foxtel has subsequently launched a standalone subscription video-on-demand (SVOD) service, Binge, which is presently offered alongside Foxtel Now.

${ }^{20}$ There is no equivalent of the catch-up services in the US market, likely because of the limited use of free-to-air broadcast reception. The high rate of multichannel subscription has led US multichannel services such as Comcast to facilitate ondemand access to current season programming in a manner similar to these catchup services. Hulu also serves this function for subscribers without multichannel services, though it is not a precise parallel to Australian broadcasters' internetdistributed services.

${ }^{21}$ Ampere Analysis, The UK VoD Market: Current Status and Future Developments (London: Ofcom/Ampere Analysis), 5. For a sophisticated analysis of complementarity and substitution in internet-distributed video, see Evens and Donders, Platform Power and Policy, 47-85.

${ }^{22}$ Luis Aguiar and Joel Waldfogel, "Netflix: Global Hegemon or Facilitator of Frictionless Digital Trade?," Journal of Cultural Economics 42 (2018): 443-44.

${ }^{23}$ We note the hybridization of these categories in services such as YouTube, which has both advertising video-on-demand (AVOD) and SVOD tiers, and in certain catch-up services (TenPlay) that have a premium ad-free tier (TenAllAccess), blurring the boundaries between AVOD and SVOD.

${ }^{24}$ The Prime Video catalog has a high proportion of older and non-premium content. Ramon Lobato and Alexa Scarlata, Australian Content in SVOD Catalogs: Availability and Discoverability, Report (Melbourne: RMIT University, 2019), 12-13.

${ }^{25}$ It is fair to ask whether any video is interchangeable, arguably a key aspect of creative goods is that they are not. However, we can imagine some titles do provide some degree of substitutability.

${ }^{26}$ Kevin Sanson and Gregory Steirer, "Hulu, Streaming, and the Contemporary Television Ecosystem," Media, Culture E Society 41 (2019): 1210-27.

${ }^{27}$ Patrik Aspers, Markets (Cambridge: Polity, 2011).

${ }^{28}$ Gregory Ferrell Lowe, Hilde Van den Bulck, and Karen Donders, Public Service Media in the Networked Society (Göteburg: Nordicom, 2018).

${ }^{29}$ Amanda D. Lotz, The Television Will Be Revolutionized, 2nd rev. ed. (NY: New York University Press, 2014).

${ }^{30}$ The case of Foxtel Now is complex. Strategically, this is an effort by a multichannel cable provider to expand its user base to those not subscribing to the multichannel service. Foxtel Now is owned by large media conglomerates (News Corp Australia 
and Telstra) but is not being used in a loss leader capacity to drive business to other businesses of those companies.

31 The figures referred to here are as per the 2018-2019 annual reports of Amazon, Inc. and Netflix, Inc. The proportion of revenues derived from Prime Video is not easily calculable due to the complex bundling of Prime Video with Prime membership. However, it is clear that the value of Prime Video to Amazon, Inc. is indirect: Prime Video makes up a very small part of a much larger corporate enterprise with multiple strategic objectives, rather than being the exclusive revenue source as for Netflix.

${ }^{32}$ Kristin Thompson, Exporting Entertainment: America in the World Film Market, 1907-1934 (London: British Film Institute, 1985).

${ }^{33}$ Karlene Lukovitz, "Netflix Toughening Criteria for Original Content Spend," Media Post, July 8, 2019, https://www.mediapost.com/publications/article/337869/ netflix-toughening-criteria-for-original-content-s.html (accessed September 26, 2019).

${ }^{34}$ Notably, multiple viewers commonly access a single subscription. Although as industry analyst Matthew Ball notes, Netflix pays for content over time in a way that makes this a more conceptual exercise than a precise cost accounting: Matthew Ball, "How the Paradox of the Term 'Original Series' Explains the Video Industry," Redef, August 27, 2018, https://redef.com/original/how-the-paradox-of-the-phraseoriginal-series-explains-the-video-industry-netflix-misunderstandings-pt-4 (accessed September 24, 2019).

${ }^{35}$ Amanda D. Lotz, "In between the Global and the Local: Mapping the Geographies of Netflix as a Multinational Service," International Journal of Cultural Studies 24 (2020): 195-215.

${ }^{36}$ For comparison, local (Australian) content comprises 11 percent of the Stan catalog, compared to 1 percent of the Netflix catalog. See Lobato and Scarlata, Australian Content in SVOD Catalogs.

${ }^{37}$ The Ampere/Variety data analyses can be found at Mandori Ravindran, "Brave New World: Meet the International Streamers Battling Netflix With Local Originals," Variety, July 30, 2019, https://variety.com/2020/tv/news/international-stream ers-originals-netflix-amazon-1234720139 and linked articles from that page.

${ }^{38}$ European Audiovisual Observatory, Film and TV Content in VOD (Strasbourg: Council of Europe, 2019), 25.

${ }^{39}$ Netflix, "Netflix's View: streaming entertainment is replacing linear TV," January 21, 2021, https://ir.netflix.net/ir-overview/long-term-view/default.aspx.

${ }^{40}$ This approach was advocated in the Australian Competition and Consumer Commission's recent Digital Platforms Inquiry: ACCC, Digital Platforms InquiryFinal Report, July 26, 2019, https://www.accc.gov.au/publications/digital-plat forms-inquiry-final-report (accessed June 18, 2020). 


\section{Bibliography}

Aguiar, Luis, and Joel Waldfogel. "Netflix: Global Hegemon or Facilitator of Frictionless Digital Trade?" Journal of Cultural Economics 42 (2018): 443-44.

Ampere Analysis. The UK VoD Market: Current Status and Future Developments. London: Ofcom/Ampere Analysis, 2019.

Aspers, Patrik. Markets. Cambridge: Polity, 2011.

Australian Competition and Consumer Commission. Digital Platforms Inquiry-Final Report. Canberra: Australian Competition and Consumer Commission, 2019. https://www. accc.gov.au/publications/digital-platforms-inquiry-final-report (accessed June 18, 2020).

Australian Communications and Media Authority. Communications Report 2018-2019. Canberra: Australian Communications and Media Authority, 2019. https://www. acma.gov.au/publications/2020-02/report/communications-report-2018-19 (accessed September 1, 2019).

Ball, Matthew. "How the Paradox of the Term 'Original Series' Explains the Video Industry." Redef, August 27, 2018. https://redef.com/original/how-the-paradox-of-thephrase-original-series-explains-the-video-industry-netflix-misunderstand ings-pt-4 (accessed September 24, 2019).

Callon, Michel, ed. The Laws of the Markets. Malden, MA: Blackwell, 1998.

Christophers, Brett. “The Law's Markets." Journal of Cultural Economy 8, no. 2 (2015): 125-43.

Crawford, Colin. "Fictitious Capital: Netflix and the New Narratives of Media Value in Platform Capitalism." In Intersections/Cross-Sections, conference proceedings, 15-24. Toronto: Ryerson University and York University, 2019.

Crawford, Colin. Netflix's Speculative Fictions: Financializing Platform Television. Lanham, MD: Rowman and Littlefield, 2020.

Cunningham Stuart, and David Craig. Social Media Entertainment: The Intersection of Hollywood and Silicon Valley. New York: New York University Press, 2019.

Dovey, Lindiwe. "Entertaining Africans: Creative Innovation in the (Internet) Television Space." Media Industries 5, no. 2 (2018): 93-110.

Doyle, Gillian. Understanding Media Economics. Thousand Oaks, CA: SAGE, 2013.

European Audiovisual Observatory. Film and TV Content in VOD Catalogues. Strasbourg: Council of Europe, 2019.

Evens, Tom, and Karen Donders. Platform Power and Policy in Transforming Television Markets. Basingstoke: Palgrave Macmillan, 2018.

Hall, Tony. "Roscoe Lecture." Liverpool John Moores University, November 2, 2017. https://www.bbc.co.uk/mediacentre/speeches/2017/tony-hall-roscoe (accessed September 17, 2019). 
Hewgill, Christian. "Disney, Netflix, Amazon: The Battle for Streaming Survival." BBC News, April 12, 2019. https://www.bbc.com/news/newsbeat-47692925 (accessed September 23, 2019).

Imre, Aniko. "HBO's e-Eutopia." Media Industries 5, no. 2 (2018): 49-68.

Jarvey, Natalie. "NBCUniversal CEO Steve Burke Explains How New Streaming Service Will Take Shape." The Hollywood Reporter, January 14, 2019. https://www.hollywoodre porter.com/news/nbcu-ceo-steve-burke-talks-forthcoming-streaming-servicefuture-hulu-impact-nbc-news-1176015 (accessed October 17, 2019).

Jenner, Mareike. Netflix and the Re-Invention of Television. Cham: Springer, 2018.

Johnson, Catherine. Online TV. London: Routledge, 2019.

Khan, Lina M. “Amazon's Antitrust Paradox.” Yale Law Journal 126 (2017): 710-805.

Lobato, Ramon, and Alexa Scarlata. Australian Content in SVOD Catalogs: Availability and Discoverability. Report. Melbourne: RMIT University, 2019.

Lotz, Amanda D. The Television Will Be Revolutionized, 2nd rev. ed. New York: New York University Press, 2014.

Lotz, Amanda D. "In between the Global and the Local: Mapping the Geographies of Netflix as a Multinational Service." International Journal of Cultural Studies 24 (2020): 195-215. https://doi.org/10.1177/1367877920953166.

Lotz, Amanda D., Ramon Lobato, and Julian Thomas. "Internet-Distributed Television Research: A Provocation." Media Industries 5, no. 2 (2018): 35-47.

Lowe, Gregory Ferrell, Hilde Van den Bulck, and Karen Donders. Public Service Media in the Networked Society. Göteburg: Nordicom, 2018.

Lukovitz, Karlene. "Netflix Toughening Criteria for Original Content Spend." Media Post, July 8, 2019. https://www.mediapost.com/publications/article/337869/netflix-tough ening-criteria-for-original-content-s.html (accessed September 26, 2019).

McDonald, Kevin, and Daniel Smith-Rowsey, eds. The Netflix Effect: Technology and Entertainment in the 21st Century. London: Bloomsbury, 2016.

Moore, Martin, and Damian Tambini, eds. Digital Dominance: The Power of Google, Amazon, Facebook, and Apple. Oxford: Oxford University Press, 2018.

Napoli, Philip M., and Robyn Caplan. "Why Media Companies Insist They're Not Media Companies, Why They're Wrong, and Why It Matters." First Monday 22, no. 5 (2017). http://dx.doi.org/10.5210/fm.v22i15.7051.

Raphael, Rina. "Netflix CEO Reed Hastings: Sleep Is Our Competition." Fast Company, November 6, 2017. https://www.fastcompany.com/40491939/netflix-ceo-reedhastings-sleep-is-our-competition (accessed October 17, 2019).

Ravindran, Mandori. "Brave New World: Meet the International Streamers Battling Netflix with Local Originals." Variety, July 30, 2019. https://variety.com/2020/tv/news / international-streamers-originals-netflix-amazon-1234720139 
Sanson, Kevin, and Gregory Steirer. "Hulu, Streaming, and the Contemporary Television Ecosystem." Media, Culture E Society 41 (2019): 1210-27.

Sherman, Alex, and Dain Evans. "How Streaming Wars between Disney, Netflix and Others Will Change TV." CNBC, August 10, 2019. https://www.cnbc.com/2019/08/10/ how-streaming-wars-between-disney-netflix-others-will-change-tv.html (accessed September 23, 2019).

Strangelove, Michael. Post-TV: Piracy, Cord-Cutting, and the Future of Television. Toronto: University of Toronto Press, 2015.

Straubhaar, Joseph, Deborah Castro, Luiz Guilherme Duarte, and Jeremiah Spence. "Class, Pay TV Access and Netflix in Latin America: Transformation within a Digital Divide." Critical Studies in Television 14, no. 2 (2019): 233-54.

Thompson, Kristin. Exporting Entertainment: America in the World Film Market, 1907-1934. London: British Film Institute, 1985.

Turner, Graeme. "Netflix and the Reconfiguration of the Australian Television Market." Media Industries 5, no. 2 (2019): 129-42.

Vonderau, Patrick. "Beyond Piracy: Understanding Digital Markets." In Connected Viewing: Selling, Streaming and Sharing Media in the Digital Age, edited by Jennifer Holt and Kevin Sanson, 99-123. London: Routledge, 2013.

Vonderau, Patrick. "The Video Bubble: Multichannel Networks and the Transformation of YouTube." Convergence 22, no. 4 (2016): 361-75.

Weiner, Jonah. “The Great Race to Rule Streaming TV.” New York Times, July 10, 2019. https:// www.nytimes.com/2019/07/10/magazine/streaming-race-netflix-hbo-hulu-ama zon.html (accessed September 23, 2019). 